\title{
Preparation and Study of Bacterial Layers on SWCNT Films with Subsequent Carbonization
}

\author{
Christian B. Fischer ${ }^{1}$, Gitta Ehrenhaft ${ }^{1}$, Alexandra Schubert-Unkmeir ${ }^{2}$ and Stefan Wehner ${ }^{*}, 1$ \\ ${ }^{I}$ Experimentalphysik III, Universität Bayreuth, Universitätsstraße 30, D-95447 Bayreuth, Germany \\ ${ }^{2}$ Institut für Hygiene und Mikrobiologie, Universität Würzburg, Josef-Schneider-Straße 2, D-97080 Würzburg, Germany
}

\begin{abstract}
Two types of bacteria were placed on the top surface of carbon nanotube films and the composite film morphology was examined using scanning electron microscopy. The interaction of bacteria with the carbonaceous film was studied after drying and subsequent heating to $1000^{\circ} \mathrm{C}$. For gram-positive bacteria, subsequent shrinkage of the bacterial layer causes film stresses and roll-up, and for the gram-negative bacteria the carbonization step seems to leave residual bacterial-derived material in-between the Single-Walled Carbon NanoTube (SWCNT) network, suggesting some type of interaction between the SWCNTs and the bacterial wall that leads to incorporation of material within the network, which then carbonizes. These observed property changes are undesirable during the lifetime of the material network, but might be welcome for its later disposal.
\end{abstract}

Keywords: SWCNT thin films, bacteria adhesion, carbonization, nanostructures, SEM.

\section{INTRODUCTION}

Adhesion of bacteria to surfaces is a common fact and causes various problems. Important topics are the interactions in sea water on surfaces, especially ships [1] or the consequences of bacteria on surfaces of implants and medical devices [2]. Staphylococcus epidermidis as typical gram-positive bacteria is able to form biofilms [3]. It is known for micro-engineered polymer surfaces that biofilm formation of Staphylococcus aureus can be postponed for an extended period of time. These observations open possibilities for medical devices: Surfaces with an engineered texture remain sterile longer than flat surfaces. The surface features are able to suppress or to limit the binding of such gram-positive bacteria and the process of biofilm formation is slowed down [4]. A similar study tested the adhesion of S.epidermidis on chemically altered surfaces. Biofilm formation on hydrophilic and hydrophobic surfaces and on such with ionic character was examined. Hydrophobic interactions between bacteria and material were found to be important for the binding to the substrate [5]. Therefore hydrophilic surfaces decrease and hydrophobic surfaces increase the bacterial adhesion $[6,7]$. The direction of all these research activities is to minimize bacterial adhesion and therefore biofilm formation by proper substrate selection and modification.

With the rise of nanotechnology a significant number of new materials are becoming popular. Various carbon-based materials were prepared to upgrade materials properties and quality. The improvement of stiffness for engineering purposes, the reduction of materials weight or the supply of higher energy density, e.g. for batteries or hydrogen storage

*Address correspondence to this author at the Experimentalphysik III, Universität Bayreuth, Universitätsstraße 30, D-95447 Bayreuth, Germany; Fax:+49-921-55-843805; E-mail: stefan.wehner@uni-bayreuth.de
[8], are major concerns in research. For different reasons they have attracted a lot of interest especially when they are paper-like. Examples are graphene oxide paper [9], membranes of conductive bacterial cellulose by incorporation of multi-wall carbon nanotubes (MWCNTs) [10], or single-wall carbon nanotube (SWCNT) films. Recently, Pushparaj et al. have reported the use of modified carbon nanotube papers as a battery applicable inside the human body as a pacemaker battery [11]. Carbon nanotube (CNT) films have been proposed as good filters for removing chemicals and bacteria from water [12]. The advantage of CNT filters is the ease of cleaning simply by ultrasonication and autoclaving [13]. Zhou et al. have shown that dispersed single-wall carbon nanotubes are able to capture even low numbers of bacteria in solution and therefore show a high ability to trap bacteria [14].

In this article we present a study using Scanning Electron Microscopy (SEM) of bacterial layers on top of SWCNT thin film as one example of such new carbon-based materials. The structural changes of the bacterial layer were examined: 1) after deposition, 2) after drying and 3) after subsequent heating ending finally in carbonization of the bacterial layer. New carbon-based materials are in contact with bacteria during their lifetime, intentionally or randomly. The interactions of two typical bacterial species very common in nature are examined. A S. epidermidis isolate has been selected as a representative for gram-positive bacteria and an E. coli isolate has been chosen as a representative for gram-negative bacteria. These two germs can be easily distributed by every person or directly from the environment, e.g. skin contact facilitates transmission during the manufacturing process or in use. Therefore these have been selected as examples for this study.

\section{MATERIALS AND METHODOLOGY}

Escherichia coli strain DH5a and Staphylococcus epidermidis strain ATCC\#35984 were kindly provided by 
the Institute of Hygiene and Microbiology, Würzburg, Germany. The SWCNTs were purchased from Carbon Nanotechnologies Inc. (CNI, 16200 Park Row, Houston, TX, USA). The carbon nanotube films were produced following standard procedures [15-17] by filtration of a suspension on a polycarbonate filter; see supporting information for a detailed description. The bacteria were deposited and accumulated by subsequent vacuum filtration to avoid mixing with the carbonaceous material. As a result it was possible to examine the interface between carbon nanotube film and bacteria film. Each film was dried in vacuum. The SEM imaging was done using a field-emission scanning electron microscope (FE-SEM) from Zeiss model LEO type 1530. SEM samples were prepared by depositing the SWCNT free standing film on an alumina plate followed by deposition of $4 \mathrm{~nm}$ of Pt. The imaging was performed at an acceleration voltage of $5 \mathrm{kV}$. The EDX-measurements were conducted at an acceleration voltage of $9 \mathrm{kV}$. The samples were analyzed after various preparation steps: (a) after deposition and (b) after the carbonization process at $1000^{\circ} \mathrm{C}$ in a vacuum chamber. It is known from other experiments [8], that a SWCNT thin film without a bacterial layer will not change during subsequent heating to $1000^{\circ} \mathrm{C}$ and cooling in vacuum.

\section{RESULTS}

\subsection{Gram-Positive Bacteria (Staphylococcus epidermidis)}

After SWCNT film production the gram-positive bacteria S. epidermidis were deposited on the top of the neat film. The deposit on the thin SWCNT surface was about twenty bacteria layers thick with a height between 6 and $8 \mu \mathrm{m}$ (Fig. 1A). The first observation was that the CNT film loaded with bacteria on one side lifts from the substrate polycarbonate filter material during drying. After removal of the substrate the free standing carbon nanotube film started to bend towards the bacteria covered side. The interaction of grampositive bacteria and carbon nanotubes is stronger than that between nanotube film and polycarbonate. It is even stronger than between the carbon nanotubes inside the film, as shown in Fig. (1B) (bending towards bacteria front) and Fig. (1C) (disrupted film).

In the next step we wanted to analyze how the SWCNT thin film covered with a bacterial layer will change during heating, especially whether the contamination of bacteria could be removed by heat. The heating was performed in the absence of air since heating of carbon-based materials results finally in carbon dioxide. The quite elevated temperature of $1000^{\circ} \mathrm{C}$ was chosen to carbonize the bacterial layer and to simulate the proposed use of carbon-based materials, e.g. HOPG $[18,19]$, in high temperature range. As seen in Fig. (2A), further destruction started during heating. The surface of the bacteria started to change during the carbonization process, finally ending in a glassy carbon-like layer. This structural change was accompanied by a change in thickness. The earlier twenty layers of S. epidermidis on top of the carbon nanotube film $(1.5-2.0 \mathrm{~nm})$ with an initial thickness between 6 and $8 \mu \mathrm{m}$ has collapsed to a homogeneous layer of some hundred nanometers up to $1 \mu \mathrm{m}$ thickness at some positions (Fig. 2).

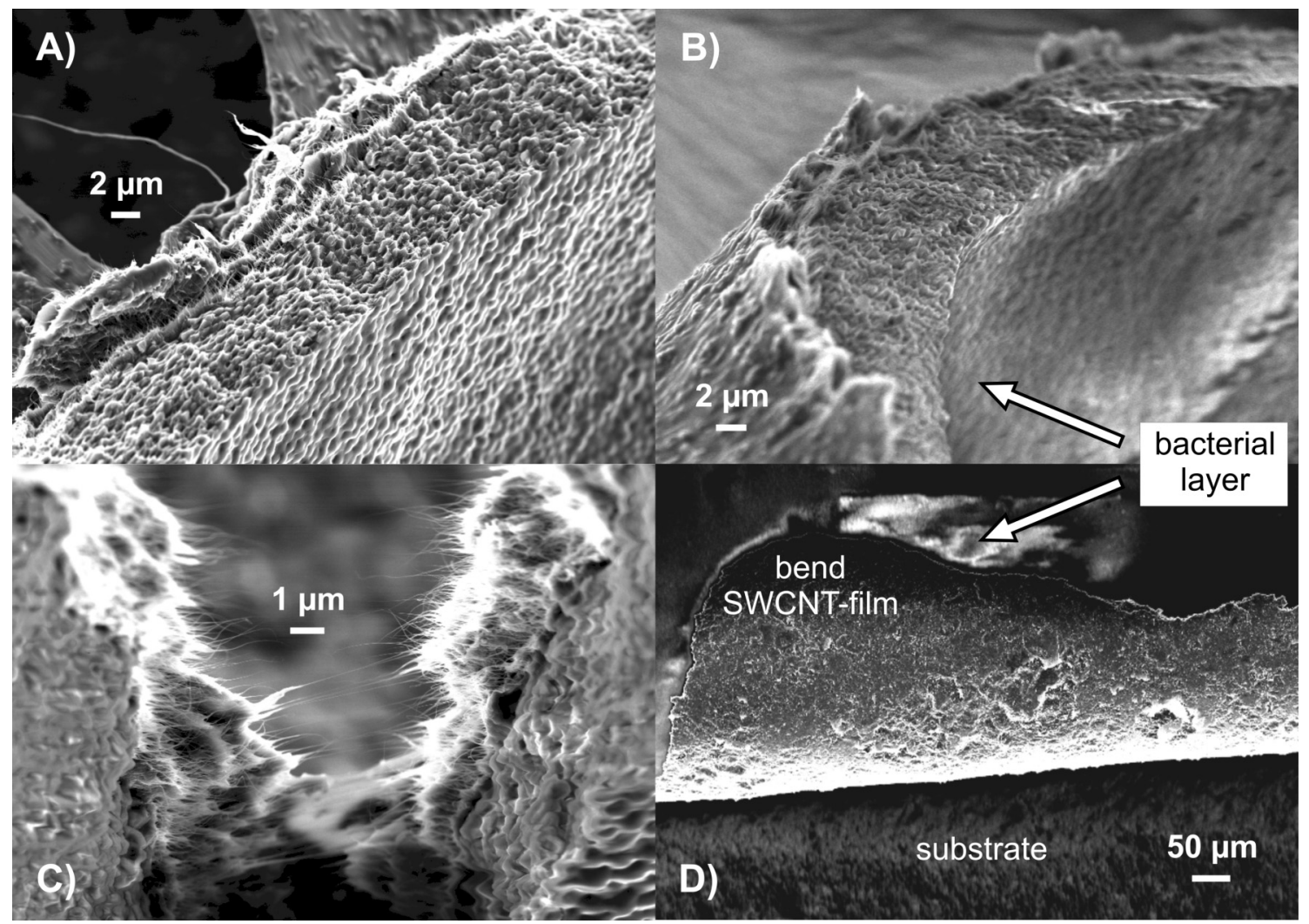

Fig. (1). SEM-images of deposited S. epidermidis bacteria on SWCNT film. (A) The bacterial growth with an average height of 6 to $8 \mu \mathrm{m}$ ( $\sim$ twenty layers) can be easily distinguished between the thin SWCNT substrate. (B) The bending of the film towards the bacterial layer is shown, which can result in a complete disruption of substrate and bacterial layer as shown in (C). (D) A zoom-out view of bend film. 

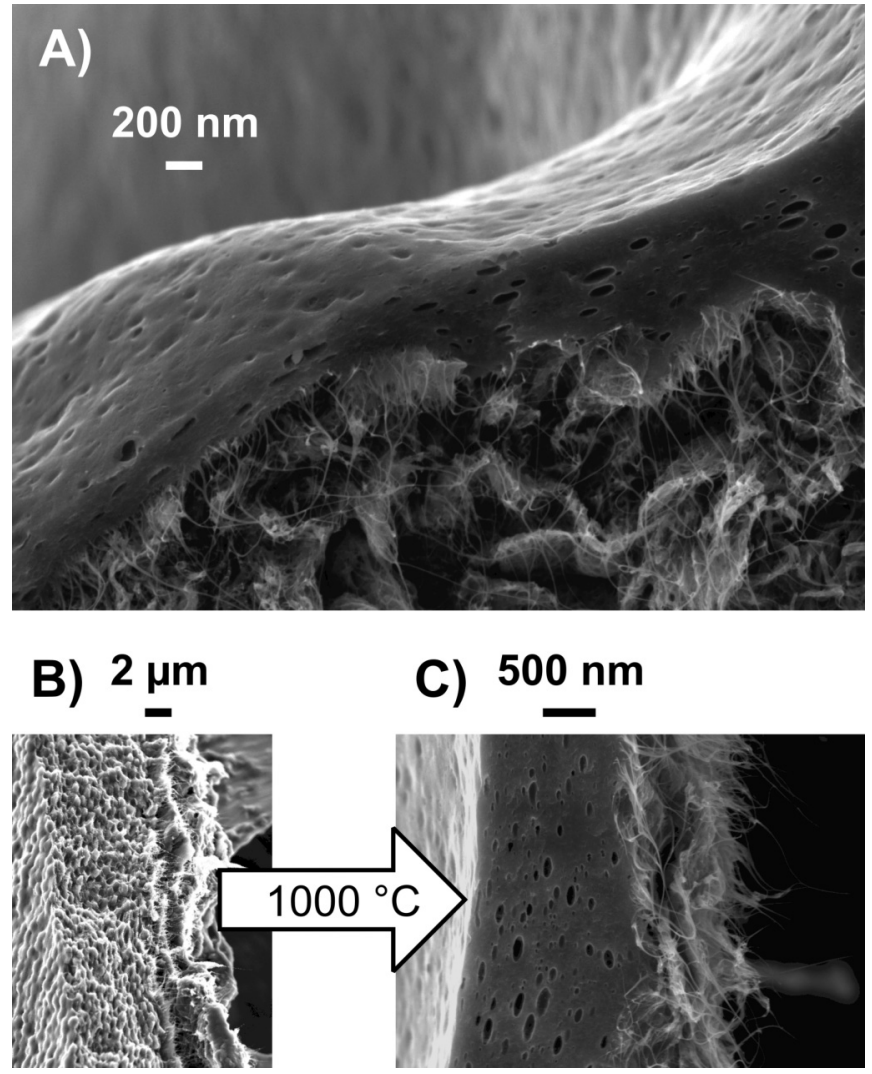

Fig. (2). (A) The former S. epidermidis layer (see Fig. 1A-C) is converted to a glassy carbon-like coverage during the carbonization process. The initial 6-8 $\mu \mathrm{m}$ of bacterial layer collapsed down to the nanometer scale. A direct comparison of both layers is shown in (B) and (C). (B) Shows the initial deposition of bacteria on the SWCNT film before and (C) the glassy carbon-like coating after carbonization.

The resistance of the sample was measured across the whole film, which has a diameter of about $9 \mathrm{~mm}$, using a handheld digital multimeter. The bacteria-covered film revealed a resistance of about $400 \mathrm{M} \Omega$, the resulting glassy carbon film shows a resistance of $60 \Omega$ which is near to the $50 \Omega$ of pure SWCNT film (for reference: highly oriented pyrolytic graphite HOPG shows about 2-3 $\Omega$ ). The attempt to clean the CNT film by carbonization resulted in a change of material properties from insulating to conducting, from flat layer to torn and bent film.

\subsection{Gram-Negative Bacteria (Escherichia coli)}

In a second setup E. coli as representative gram-negative bacteria was filtered on a neat CNT film. Some key differences were observed: Firstly, the gram-negative bacteria film does not detach itself as a layered film from the substrate. Secondly, no cracks or rupture of the surface occurred.

As seen in Fig. (3A, B) the E. coli bacteria have mainly filled the cavities between the carbon nanotubes. No bending and no shrinking were observed during carbonization. At first glance one would argue that E. coli are not destroying the structure of CNT film. This is true from the macroscopic point of view, form and structural integrity have been conserved (Fig. 3C). But in Fig. (3D) it can be seen that on a microscopic level the surface texture has changed. The spaces within the nanotube
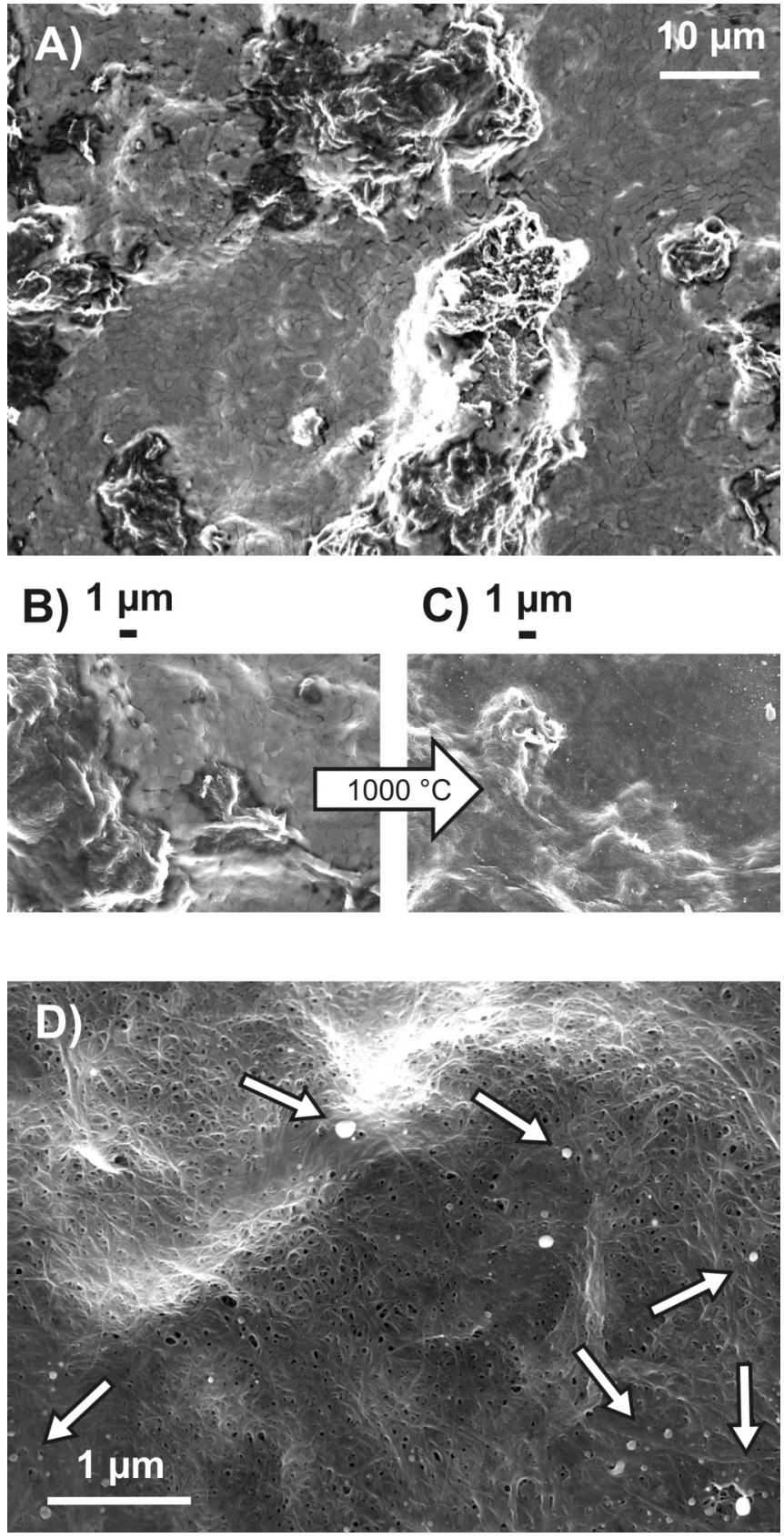

Fig. (3). SEM-images of deposited E. coli bacteria on SWCNT film. (A) The filling with bacteria in the cavities between the carbon nanotubes is shown. Irregular structures of CNTs are left. (B) The coverage of SWCNT film before and (C) after the carbonization process. The CNTs can be identified but the bacteria seem to be replaced by a shady like coverage. (D) A zoom-in view of the situation in (C) is given. During carbonization the interior of the bacteria is converted to mineral salt (indicated by white arrows) and black shadow-like regions.

network have been filled with material (Fig. 4). The material in the interior of the bacteria has spread over a wide region on the surface (indicated with arrows in Fig. 3D).

These observations have triggered further studies, since the influence of the thickness of the bacterial film on top has to be analyzed in more detail. The influence of the characteristic of gram-positive bacteria will also have to be looked at more closely. And a third aspect has to be thought about namely 

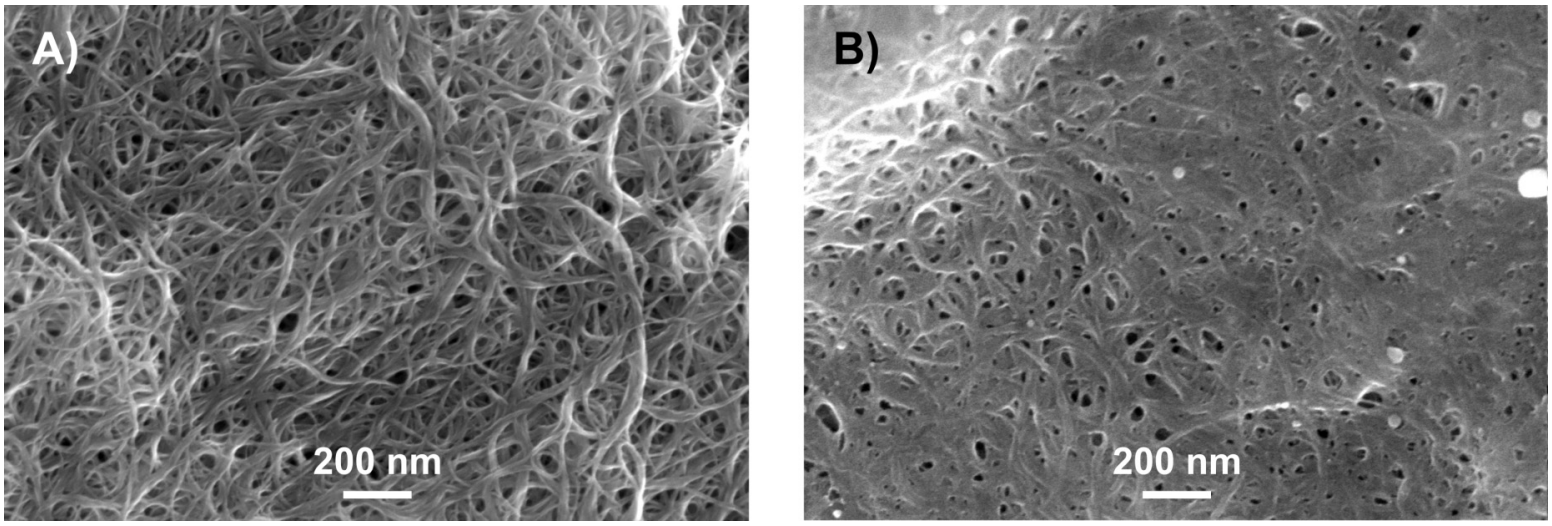

Fig. (4). Higher resolution SEM-pictures are shown for the direct comparison of a typical clean SWCNT (A) with the carbonized film which was initially covered with a thin layer of $E$. coli $(\mathbf{B})$. In $(\mathbf{B})$ the coverage of the bacteria's interior around the tubes and mineral salts can be clearly seen. The single tubes seem to be stuck together. The entire film is finally contaminated and cleaning cannot be achieved by heating up to $1000{ }^{\circ} \mathrm{C}$.

whether the changes be different if the bacterial layer has been formed by growth of living organisms instead of filtration out of suspension on top of the SWNCT thin film.

\section{DISCUSSION AND CONCLUSION}

This study has shown for the first time to the authors' knowledge that bacteria and carbon-based materials interact at the expense of the material. Structural damage on a SWNCT film was observed during drying and carbonization of the bacterial layer. Each attempt to remove the deposited bacteria resulted in more severe damage of the material, macroscopically evident for gram-positive bacteria and microscopically for gram-negative bacteria.

Since contact with bacteria cannot be excluded, one has to be aware that common bacteria can interact with new carbonbased materials in an undesirable manner. On the other hand this might help to decompose carbon-based materials after their lifespan.

\section{ACKNOWLEDGEMENTS}

The authors thank Jürgen Küppers for supporting this study.

\section{SUPPLEMENTARY DATA}

Supplementary data associated with this article can be found, in the online version, at www.bentham.org/open/tossj

\section{REFERENCES}

[1] Cooksey KE, Wigglesworth-Cooksey B. Adhesion of bacteria and diatoms to surfaces in the sea. Aquat Microb Ecol 1995; 9: 87-96.

[2] Messersmith PB, Textor M. Enzymes on nanotubes thwart fouling. Nat Nanotechnol 2007; 2: 138-9.

[3] O'Gara JP, Humphreys H. Staphylococcus epidermidis biofilms: importance and implications. J Med Microbiol 2001; 50: 582-7.

[4] Chung KK, Schumacher JF, Sampson EM, Burne RA, Antonelli $\mathrm{PJ}$, Brennan AB. Impact of engineered surface microtopography on biofilm formation of Staphylococcus aureus. Biointerphases 2007; 2: 89-94.

[5] Vacheethasanee K, Temenoff JS, Higashi JM, et al. Bacterial surface properties of clinically isolated Staphylococcus epidermidis strains determine adhesion on polyethylene. J Biomed Mater Res A 1998; 42: 425-32.

[6] MacKintosh EE, Patel JD, Marchant RE, Anderson JM. Effects of biomaterial surface chemistry on the adhesion and biofilm formation of Staphylococcus epidermidis in vitro. J Biomed Mater Res A 2006; 78: 836-42.

[7] Keselowsky BG, Collard DM, Garcia AJ. Surface chemistry modulates fibronectin conformation and directs integrin binding and specificity to control cell adhesion. J Biomed Mater Res A 2003; 66: 247-59.

[8] Zecho T, Andree A, Fischer CB, Le Lay M, Küppers J. Weakly chemisorbed hydrogen on graphite and carbon nanotubes. Will be published elsewhere.

[9] Dikin DA, Stankovich S, Zimney EJ, et al. Preparation and characterization of graphene oxide paper. Nature 2007; 448: 45760 .

[10] Yoon SH, Jin HJ, Kook MC, Pyun YR. Electrically conductive bacterial cellulose by incorporation of carbon nanotubes. Biomacromolecules 2006; 7: 1280-4.

[11] Pushparaj VL, Shaijumon MM, Kumar A, et al. Flexible energy storage devices based on nanocomposite paper. Proc Nat Acad Sci USA 2007 ; 104: 13574-7.

[12] Savage N, Diallo MS. Nanomaterials and water purification: opportunities and challenges. J Nanopart Res 2005; 7: 331-42.

[13] Srivastava A, Srivastava ON, Talapatra S, Vajtai R, Ajayan PM. Carbon nanotube filters. Nat Mater 2004; 3: 610-3.

[14] Zhou R, Wang P, Chang HC. Bacteria capture, concentration and detection by alternating current dielectrophoresis and self-assembly of dispersed single-wall carbon nanotubes. Electrophoresis 2006; 27: $1376-85$

[15] O’Connell MJ, Boul P, Ericson LM, et al. Reversible watersolubilization of single-walled carbon nanotubes by polymer wrapping. Chem Phys Lett 2001; 342: 265-71.

[16] Hennrich F, Lebedkin S, Malik S, et al. Preparation, characterization and applications of free-standing single walled carbon nanotube thin films. Phys Chem Chem Phys 2002; 4: 22737.

[17] Moore VC, Strano MS, Haroz EH, Hauge RH, Smalley RE. Individually suspended single-walled carbon nanotubes in various surfactants. Nano Lett 2003; 3: 1379-82.

[18] Zecho T, Güttler A, Küppers J. A TDS study of D adsorption on terraces and terrace edges of graphite (0001) surfaces. Carbon 2004; 42: 609-17.

[19] Güttler A, Zecho T, Küppers J. Adsorption of $\mathrm{D}(\mathrm{H})$ atoms on $\mathrm{Ar}$ ion bombarded (0001) graphite surfaces. Surf Sci 2004; 570: 218 26. 